\title{
Maskless etching of silicon using patterned microdischarges
}

\author{
R. M. Sankaran and K. P. Giapis ${ }^{\text {a) }}$ \\ Division of Chemistry and Chemical Engineering, California Institute of Technology, \\ Pasadena, California 91125
}

(Received 18 April 2001; accepted for publication 6 June 2001)

\begin{abstract}
Microdischarges in flexible copper-polyimide structures with hole diameters of $200 \mu \mathrm{m}$ have been used as stencil masks to pattern bare silicon in $\mathrm{CF}_{4} / \mathrm{Ar}$ chemistry. The discharges were operated at 20 Torr using the substrate as the cathode, achieving etch rates greater than $7 \mu \mathrm{m} / \mathrm{min}$. Optical emission spectroscopy provides evidence of excited fluorine atoms. The etch profiles show a peculiar shape attributed to plasma expansion into the etched void. Forming discharges in multiple hole and line shapes permits direct pattern transfer in silicon and could be an alternative to ultrasonic milling and laser drilling. (C) 2001 American Institute of Physics.
\end{abstract}

[DOI: $10.1063 / 1.1388867]$

Microdischarges have gained recent attention for several characteristics such as high-pressure operation and intense UV radiation. ${ }^{1-3}$ Optical studies in neon discharges have shown the presence of excited ionic states that lie more than $50 \mathrm{eV}$ above the ground state. ${ }^{4}$ Furthermore, excimer formation in these discharges suggests a relatively large concentration of high-energy electrons. ${ }^{5-7}$ Such electrons should assist in the production of reactive radicals at high pressures, rendering microdischarges suitable for materials processing. While the use of these plasmas as light sources has been studied, to our knowledge, their potential as a reactive source has not yet been explored.

A materials application of microdischarges that takes advantage of their size would be maskless pattern transfer. Since discharges can be formed in structures as small as 50 $\mu \mathrm{m},{ }^{8}$ wafers could be etched directly thus eliminating the need for a lithographic step. Furthermore, the ability to form microdischarges in flexible structures ${ }^{9}$ could allow the patterning of curved surfaces such as cylinders and spheres. While the length scales over which these plasmas are formed may not be small enough for microelectronic applications, this patterning technique could assist in the fabrication of microelectromechanical systems where dimensions are often on the order of $10-500 \mu \mathrm{m} .^{10}$

This letter reports the operation of microdischarges in $\mathrm{CF}_{4} / \mathrm{Ar}$ gas mixtures and examines their use in patterning silicon. Two-layer structures, which act as the stencil mask, were made from copper foils (100 $\mu \mathrm{m}$ thick, $99.995 \%$ pure) spin coated with polyimide films as described in the literature. ${ }^{9}$ These materials were chosen for their flexibility and degradation resistance when exposed to fluorine. Holes and slots were drilled or cut out mechanically in the twolayer structure to produce a desired pattern. Either a drilled copper foil or, in the case of etch experiments, a blanket $n$-type $\mathrm{Si}(100)$ wafer was pressed against the mask. A schematic of the latter structure is shown in Fig. 1. The assembly was then placed in a reactor chamber and was pumped to 1 $\times 10^{-6}$ Torr. Silicon wafers were cleaned prior to etching by

a)Electronic mail: giapis@cheme.caltech.edu dipping in a dilute $\mathrm{HF}$ solution $\left(1-5 \%\right.$ in $\left.\mathrm{H}_{2} \mathrm{O}\right)$ for $1 \mathrm{~min}$ and rinsing in deionized water.

Microdischarges operated in direct curent mode are typically formed at 20 Torr with inflow of $75 \mathrm{sccm} \mathrm{Ar}$ and 25 sccm $\mathrm{CF}_{4}$. Emission spectra from a microdischarge operated at $1.5 \mathrm{~mA}$, employing a copper cathode with a $200 \mu \mathrm{m}$ diameter hole, confirm the presence of reactive species [see Fig. 2(a)]. Since Ar dominates, only the most intense fluorine atom lines (indicated by star) are visible at 685.6, 690.2, and $703.7 \mathrm{~nm}$. Emission spectra of pure $\mathrm{CF}_{4}$ microdischarges at 20 Torr [see Fig. 2(b)] show stronger $\mathrm{F}$ atom lines and are similar to those obtained in conventional rf plasmas at much lower pressures. ${ }^{11}$

In the etch experiments, the $\mathrm{Si}$ substrate served as the cathode. This configuration prevented independent control of the discharge voltage and current. When a drilled metal electrode was placed between the dielectric and silicon to separate discharge operation from the substrate, the etching was characterized by low rates due to deposition of sputtered cathode material on the Si surface. In contrast, the preferred configuration yielded high etch rates perhaps due to direct contact between the discharge and the substrate. After a discharge was initiated, the device operating voltage was maintained at $400 \mathrm{~V}$ for the duration of the experiment. Etching of the substrate alters the shape of the cathode and influences both the operating voltage and current. If the voltage is kept constant, the discharge current increases almost linearly with etch time (Fig. 3) concomitant with the increase in cathode surface area. Assuming that it is constant over the entire cathode hole surface, the current density appears not to change with time.

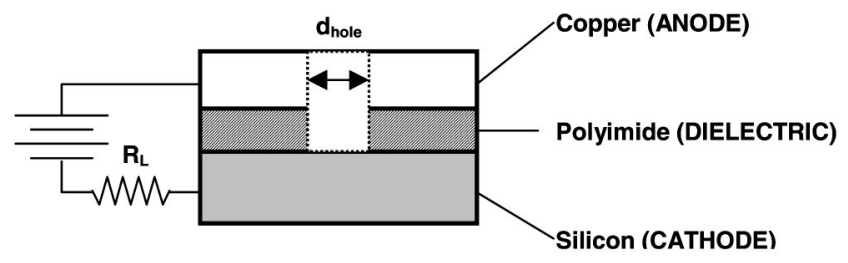

FIG. 1. Schematic diagram of setup used for single hole etching is shown. The circuit includes a current-limiting resistor $\left(R_{L}=136.6 \mathrm{k} \Omega\right)$. 


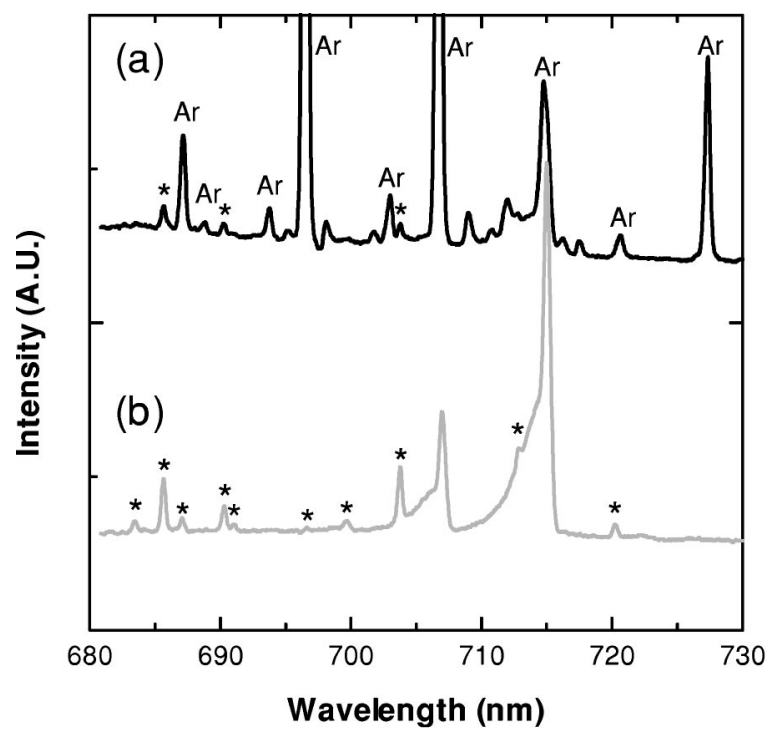

FIG. 2. Emission spectra of $\mathrm{CF}_{4} / \mathrm{Ar}$ and $\mathrm{CF}_{4}$ microdischarges operated at $1.5 \mathrm{~mA}$ and 20 Torr are shown. Additional conditions: (a) $75 \mathrm{sccm}$ Ar plus $25 \mathrm{sccm} \mathrm{CF}_{4}$, plasma potential $=370 \mathrm{~V}$ and (b) $25 \mathrm{sccm} \mathrm{CF}_{4}$, plasma potential $=490 \mathrm{~V}$ are shown.

Scanning electron microscope (SEM) images of etched substrates were taken to determine etch rates and profiles. Figure 4 shows profiles obtained after etching for 10 and 15 min. The same stencil mask with a $200 \mu \mathrm{m}$ diameter hole was used to etch several wafers with no observable damage to the mask. Early on [Fig. 4(a)], the profile showed good pattern transfer with minimal dimension loss in the substrate but rounded bottom profile. As etching continued, erosion of the sidewalls occurred which caused a bowl-shaped profile [Fig. 4(b)]. During the etch times studied, there was very little undercutting of the mask. It is hypothesized that the bowl-shaped profile is a result of the expansion of the plasma into the etched void. As the plasma fills this volume, the sheath may conform to the shape of the cavity. This could cause ion bombardment of the cavity in a spatially uniform fashion, resulting in etching of both the bottom of the hole as well as the sidewalls. Similar profiles were reported in submillimeter hollow cathode discharges operated in $\mathrm{Ne}$, albeit

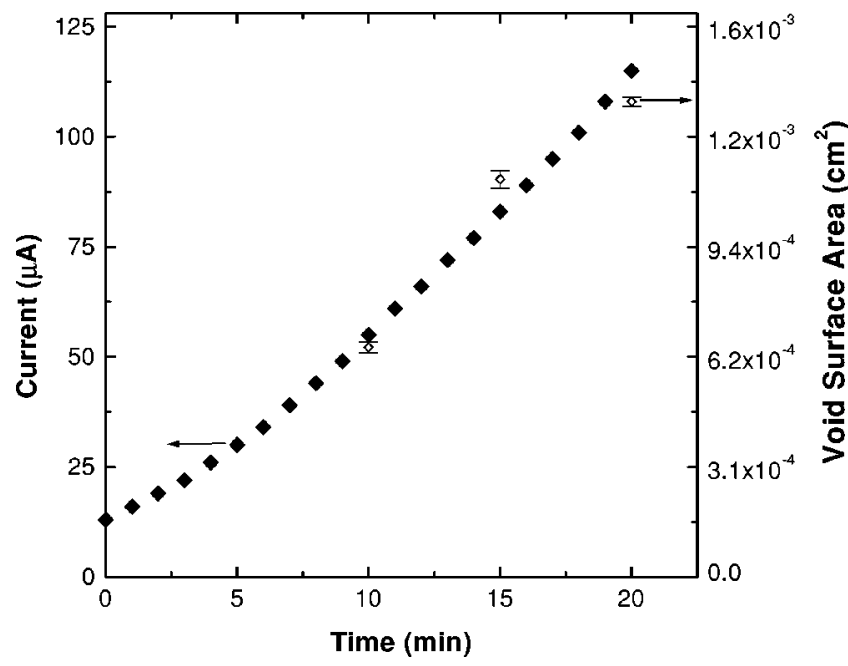

FIG. 3. Discharge current vs time for etching a $200 \mu \mathrm{m}$ hole in $n$-type $\mathrm{Si}(100)$ is shown. The plasma potential was kept constant at $400 \mathrm{~V}$. Also

shown are estimates of the surface area of the void etched into Si. $200 \mu \mathrm{m}$ width are shown.
Downloaded 30 Apr 2006 to 131.215.240.9. Redistribution subject to AlP license or copyright,
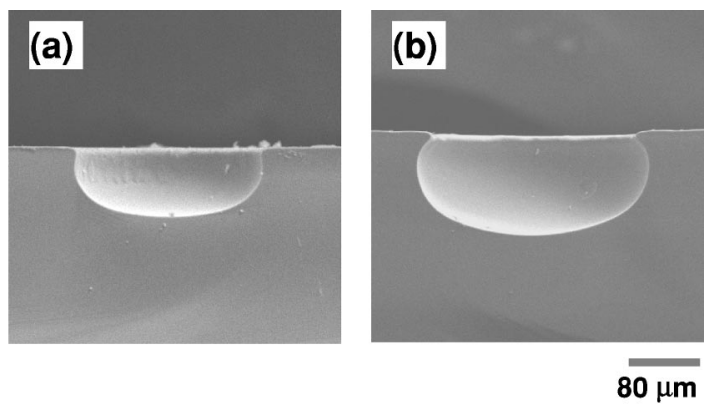

FIG. 4. SEMs of single holes etched in silicon using a stencil mask with 200 $\mu \mathrm{m}$ diameter hole after (a) $10 \mathrm{~min}$ and (b) $15 \mathrm{~min}$ are shown. Process conditions: Pressure $=20$ Torr, flow rates $=75 \mathrm{sccm}$ Ar plus $25 \mathrm{sccm} \mathrm{CF}_{4}$, and plasma potential $=400 \mathrm{~V}$.

TABLE I. Maximum width $(w)$ and depth $(d)$ of holes etched in silicon for various etch times are shown. The corresponding etch rates are also listed.

\begin{tabular}{ccccc}
\hline \hline $\begin{array}{c}\text { Time } \\
(\mathrm{min})\end{array}$ & $\begin{array}{c}w \\
(\mu \mathrm{m})\end{array}$ & $\begin{array}{c}\text { Rate in } w \\
(\mu \mathrm{m} / \mathrm{min})\end{array}$ & $\begin{array}{c}d \\
(\mu \mathrm{m})\end{array}$ & $\begin{array}{c}\text { Rate in } d \\
(\mu \mathrm{m} / \mathrm{min})\end{array}$ \\
\hline 10 & 210 & 1.0 & 77 & 7.7 \\
15 & 258 & 4.8 & 112 & 7.0 \\
20 & 274 & 1.6 & 129 & 3.4 \\
\hline \hline
\end{tabular}
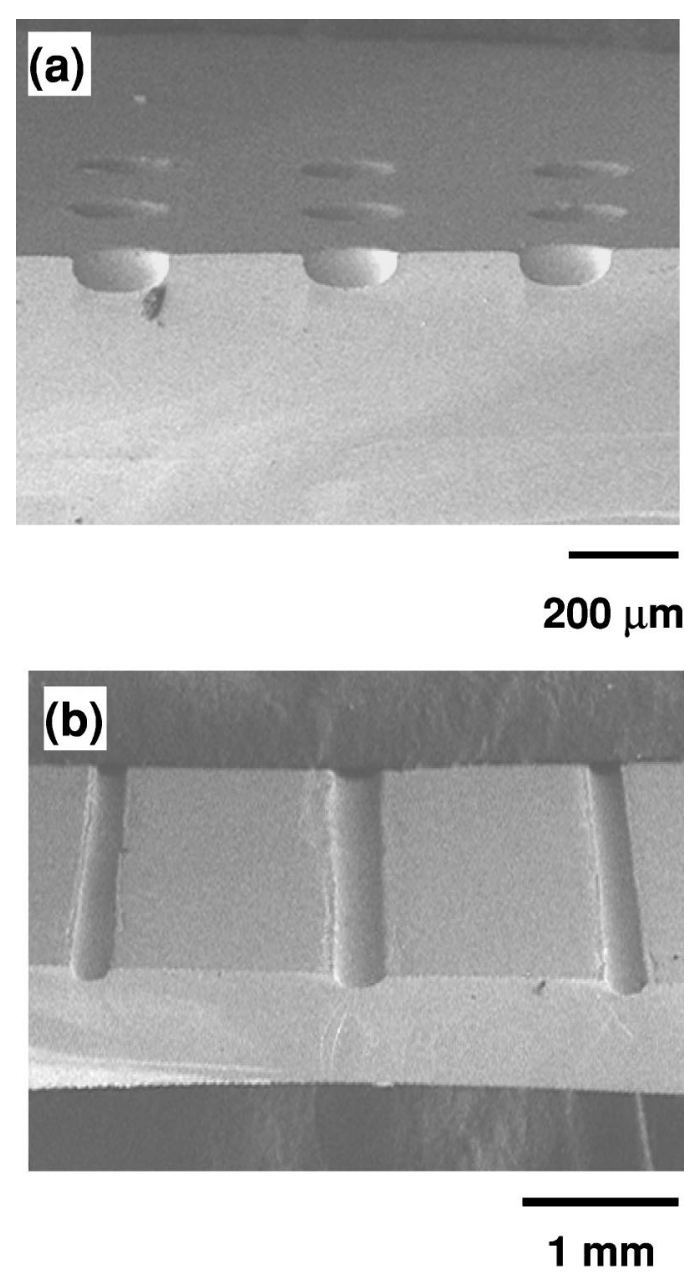

FIG. 5. SEMs of silicon substrates after direct pattern transfer using a stencil mask with (a) $3 \times 3$ array of $200 \mu \mathrm{m}$ diameter holes and (b) three slots of $200 \mu \mathrm{m}$ width are shown 
due to sputtering. ${ }^{12}$ In that case, initially cylindrical holes approached a stable spherical profile.

In order to quantify these results, we have determined the horizontal and vertical etch rates by measuring the maximum width and depth of the profiles as a function of time (Table I). Initial vertical etch rates are as high as $7.7 \mu \mathrm{m} / \mathrm{min}$, but decrease with further etching. Since the current density appears unchanged with etch time when the plasma potential is held constant, the reduction in the vertical etch rate may be due to depletion of reactive neutrals and etch product accumulation in the hole, that is, conductance limitations.

Using the same configuration and operating conditions as for single hole etching, we have etched arrays of $200 \mu \mathrm{m}$ holes. For the same operating voltage, an array of $n$ holes required a discharge current about $n$ times larger than that for a single hole. Figure 5(a) shows a Si wafer etched for $10 \mathrm{~min}$ using a stencil mask with an array of nine $200 \mu \mathrm{m}$ holes. Etching proceeded uniformly in each hole and produced profiles nearly identical to those seen for individual holes. The ability to etch arrays of holes is especially attractive for fabrication of microdischarge devices in silicon. ${ }^{4}$ As a proof-ofconcept, we have successfully initiated discharges in pure Ar after etching structures in silicon and evacuating the chamber from any reactive fluorine radicals. We have not yet studied differences in the discharge characteristics due to the shape of the cathode. While microdischarges are normally operated in holes, we have also extended our patterning method to other shapes. Figure 5(b) illustrates a result for etching silicon using a stencil mask with three parallel lines, each 200 $\mu \mathrm{m}$ wide. Even crossed lines and other combinations of shapes can be transferred; apparently, for the thickness of the mask tried, one-dimensional confinement is sufficient for the discharge to form in such patterns.
In summary, the application of microdischarges in direct pattern etching of silicon is shown to be possible with selflimitations because of the expansion of the plasma into the etched area. The high etch-rates coupled with the emission spectra show that microdischarges could be a useful source of radicals for materials processing. Power requirements to operate the discharge are less than $50 \mathrm{~mW}$ to etch a single hole to a depth of $100 \mu \mathrm{m}$. The possibility of etching complex patterns in silicon could have important applications in micromachining, including the production of arrays of microdischarges in silicon.

This material was based on work supported by NSF (ECS-9729968).

${ }^{1}$ K. H. Schoenbach, R. Verhappen, T. Tessnow, and F. E. Peterkin, Appl. Phys. Lett. 68, 1 (1996).

${ }^{2}$ A. El-Habachi and K. H. Schoenbach, Appl. Phys. Lett. 73, 885 (1998).

${ }^{3}$ A. El-Habachi and K. H. Schoenbach, Appl. Phys. Lett. 72, 22 (1998).

${ }^{4}$ J. W. Frame, D. J. Wheeler, T. A. DeTemple, J. G. Eden, Appl. Phys. Lett. 71, 1165 (1997).

${ }^{5}$ P. Kurunczi, H. Shah, and K. Becker, J. Phys. B 32, L651 (1999).

${ }^{6}$ K. H. Schoenbach, A. El-Habachi, W. Shi, and M. Ciocca, Plasma Sources Sci. Technol. 6, 468 (1997).

${ }^{7}$ A. El-Habachi, W. Shi, M. Moselhy, R. H. Stark, and K. H. Schoenbach, J. Appl. Phys. 88, 3220 (2000).

${ }^{8}$ S. J. Park, J. Chen, C. Liu, and J. G. Eden, Appl. Phys. Lett. 78, 419 (2001).

${ }^{9}$ S. J. Park, C. J. Wagner, C. M. Herring, and J. G. Eden, Appl. Phys. Lett. 77, 199 (2000).

${ }^{10}$ B. Cho, J. Ryu, S. Hwang, G. Lee, and S. H. Moon, J. Vac. Sci. Technol. B 18, 2769 (2000).

${ }^{11}$ W. R. Harshbarger, R. A. Porter, T. A. Miller, and P. Norton, Appl. Spectrosc. 31, 1 (1977).

${ }^{12}$ A. D. White, J. Appl. Phys. 30, 711 (1959). 